\title{
The gradual emergence of sex differences in aggression: alternative hypotheses
}

\author{
DALE F. HAY* \\ School of Psychology, Cardiff University, UK
}

\begin{abstract}
Nearly a century of observational studies and more recent longitudinal surveys reveal that, in infancy, girls and boys use force at similar rates. Over the next few years boys become significantly more aggressive. Alternative hypotheses accounting for the widening gender gap are evaluated. These include hypotheses about normative patterns of male escalation and female desistance; boys' preference for active play that promotes aggression; girls' tendency to hide aggression; girls' use of alternative forms of aggression; boys' increased risk for the cognitive and emotional problems that are linked to aggression; boys' sensitivity to situational triggers of aggression; and boys' vulnerability to adverse rearing environments. The evidence bearing on each hypothesis is mixed. In general, the overall difference between the sexes appears to be produced by a minority of boys who deploy aggression at high rates. Three general principles govern the emergence of sex differences in aggression: female precocity, male vulnerability, and the salience of sex as a social category that shapes children's lives.
\end{abstract}

\section{INTRODUCTION}

When they completed their classic review of the literature on psychological sex differences, Maccoby \& Jacklin (1974) concluded that many differences between men and women had been overstated, but males are definitely more aggressive than their female counterparts. Over 30 years later that conclusion still stands. Nevertheless, in the first 2 years of life, when aggression first emerges in the human repertoire, sex differences are not pronounced (for a review, see Hay, 2005). Reviews of the clinical literature show that boys' elevated risk for disruptive behaviour disorders emerges gradually over the preschool years (Keenan \& Shaw, 1997; Loeber \& Hay, 1997). Diagnostic studies of preschool samples do not provide consistent

* Address for correspondence: Professor Dale F. Hay, School of Psychology, Cardiff University, Park Place, Cardiff CF10 3AT, UK. (Email: haydf@Cardiff.ac.uk) evidence for sex differences in disruptive behaviour disorders (Egger \& Angold, 2006). However, by 5 years of life, boys are three times as likely as girls are to have clinically diagnosed conduct disorder (Kim-Cohen et al. 2005). What, then, are the developmental processes that underlie the emergence and exaggeration of sex differences in aggression? In this paper, I consider some alternative hypotheses. First, however, it is important to consider the major theoretical debate about the origins of aggression.

\section{NATURE AND NURTURE}

The study of sex differences in aggression is embedded in more general debates about whether children learn to be aggressive. With a decline in social learning perspectives on children's development has come an emphasis on the fundamental biological origins of 
aggression. For example, Tremblay \& Nagin (2005) have argued that:

physical aggression is not a behavior children learn, like reading or writing, nor an illness children 'catch', like poliomyelitis or smallpox. It is rather a behavior like crying, eating, sleeping, grasping, throwing, and running, which young humans exhibit when the physiological structure is in place, but then learn to control with experience. The learningto-control process implies regulating one's needs to accommodate those of others, and this process can be labelled 'socialization' (p. 95).

Tremblay and Nagin's claim implies that aggression is a natural and adaptive behavioural category that has evolved in the human species (see also Koops, 2001). In line with this view, the adaptive value of aggression is thought to be especially salient for males, with the male capacity for aggression maintained through processes of sexual selection (Archer \& Côté, 2005).

It is not clear what infants do in fact learn about aggression, nor whether girls and boys learn different things. Most of the experiments undertaken in the social learning tradition focused on children of preschool age or older, using stimuli that assessed aggressive play, such as the classic Bobo bouncing toy (Bandura et al. 1963) or dolls and doll houses (e.g. Hollenberg \& Sperry, 1951). It is only in recent years that there has been renewed attention to the early origins of aggression (e.g. Tremblay, 2000; Tremblay \& Nagin, 2005). By evaluating alternative explanations of the emerging sex difference in aggression, we can consider how biological and social influences work together in the early years to either foster or control children's aggressive tendencies.

\section{ALTERNATIVE HYPOTHESES}

At least eight possible hypotheses about the emergence of sex differences in aggression can be advanced:

(1) Girls never develop a propensity for aggression, and engage primarily in prosocial or passive behaviour.

(2) Boys and girls initially show similar levels of aggression, but, starting in infancy and early childhood, boys' use of aggression escalates, while girls desist more rapidly and more effectively.

(3) Boys and girls play with other children in different ways. Boys' style of play is more likely to lead to physical aggression.

(4) Girls continue to be just as aggressive as boys are, but their behaviour is more covert and less likely to occur under the eyes of adults.

(5) Girls continue to be just as aggressive as boys are, but their aggression is qualitatively different, being more verbal and more likely to involve the manipulation of interpersonal relationships.

(6) Boys are more likely than girls to have cognitive and emotional deficits, which make it hard for them to deal with other people. These problems promote the use of aggressive tactics in social situations.

(7) Boys are more sensitive than girls are to situational factors that provoke aggression.

(8) Boys are more affected by adverse rearing environments; thus, it is not all boys but those who are exposed to biological and social risk factors who are highly aggressive.

\section{Hypothesis 1: Girls are never very aggressive}

The strong claim that girls never develop the ability to be aggressive can be rejected in view of the fact that, when infants first begin to use force against their companions, girls and boys bite, hit and push their peers (Eckerman et al. 1975; Bakeman \& Brownlee, 1982; Hay \& Ross, 1982; Caplan et al. 1991; Hay et al. 2000, unpublished observations; Alink et al. 2006). In observational studies of infants and toddlers, there are few striking differences in the use of force by girls and boys. In some studies, aggression occurs so infrequently that tests for sex differences could not be made (e.g. BrooksGunn \& Lewis, 1979); in most other cases, no significant sex differences are observed.

It is of course undesirable to accept the null hypothesis of no difference between the sexes, and the absence of significant differences may be due to insufficient statistical power in small observational studies (see Archer \& Côté, 2005). In a larger study of 104 two-year-olds (Rubin et al. 1998), girls had lower scores than boys did on a global measure of aggression. However, in that sample, the girls and boys did not 
differ significantly on a composite variable that measured physical aggression (hitting, pushing, punching and kicking). Nor were there sex differences in adult-rated externalizing problems.

Recent surveys of large, representative samples have shown that the display of aggression is a ubiquitous phenomenon in the toddler years, shown by girls as well as boys. For example, in a representative sample of 562 19-month-old twins, very few were reported never to show aggressive behaviour (Dionne et al. 2003). In a nationally representative Dutch sample, parents have reported sex differences in physical aggression starting around 24 months of age (Alink et al. 2006). The parents' reports of infants' and toddlers' externalizing problems showed an increasing sex difference from 12 to 36 months of age (van Zeijl et al. 2006). Thus, the starting point is one of similarity between the sexes.

\section{Hypothesis 2: Boys escalate and girls desist}

The widening gap in the rates of aggression shown by girls and boys may emerge because boys escalate in terms of the frequency with which they show aggression, while girls desist from the use of force. A pattern of increasing male aggression could be underpinned by maturational factors, including hormonal change, physical growth and language development.

\section{The testosterone surge}

Increasing testosterone levels in young boys might affect the development of aggression. However, a link between testosterone and physical aggression in early development, although demonstrated in other primate species, has not been clearly shown in young humans (van Goozen, 2005). The postnatal testosterone surge in humans appears to be correlated with sex-specific morphological change, not with behaviour.

\section{Physical growth}

The emerging sex difference in rates of aggression could be due to physical maturation and the increasing dimorphism between males and females. Eventually human males are larger and stronger than their female counterparts, and can inflict more damage on their companions. A cohort study of children from Mauritius showed that larger body size at age 3 was associated with later aggression; however, this was true for both sexes (Raine et al. 1998). Indeed, the two sexes remain very similar in musculoskeletal development until puberty (Cairns \& Kroll, 1994), and so the sex difference in aggression predates the disparity in body size and muscular strength. However, one physical difference might contribute to diverging rates of aggression. Sex differences in forearm strength, which might make boys' hitting more effective, emerge in early childhood (Cairns \& Kroll, 1994).

\section{Language acquisition}

It is possible that the emerging difference between the sexes is influenced by the maturational advantage held by girls over boys with respect to language development. Young girls may find it easier to adopt verbal strategies to resolve their disputes with other people. For example, girls develop linguistic competence and conversational skills sooner than boys do (Dionne et al. 2003; Hay, 2006), and thus are better able to diffuse conflict with words, and so do not need to resort to force. For example, the ability to deal with conflict by claiming objects ('Mine!') is initially associated with grabbing those objects, but predicts later sharing, not aggression (Hay, 2006). The more rapid maturation shown by girls in infancy may foster many dimensions of self-regulation at earlier ages, which in turn promotes desistance from aggression.

\section{Individual trajectories}

Nevertheless, before accepting general hypotheses about maturational processes in girls and boys, we must consider individual differences. Recent work on the early development of aggression has shown that not all boys are equally aggressive. It is important to distinguish subgroups of children who follow different developmental trajectories, rather than simply looking for general differences between girls and boys. Although, in general, the use of physical aggression seems to peak around $2 \frac{1}{2}$ years of age (Holmberg, 1980; Hay, 2005; Tremblay \& Nagin, 2005), the overall developmental trend is 
not representative of all children. In a number of different samples, trajectory analyses have identified a subgroup of children who show high levels of aggression, with maintenance or escalation of the use of aggression over time (Broidy et al. 2003). Other children in those samples show a pattern of desistance over time.

The high, stable trajectory begins in early childhood (NICHD Early Child Care Research Network, 2004; Campbell et al. 2006; Côté et al. 2006). In a large birth cohort in the province of Québec, primary caregivers were asked to report on their children's physical aggression at intervals between 17 and 42 months of age (Tremblay et al. 2004). Some children were never reported to show much aggression, and their level of aggression remained at low rates over the sequence of assessments; this subgroup had a preponderance of girls $(61 \%$ of the group). Another subgroup (13.9\% of the sample) used physical aggression at high rates at the initial assessment, and then showed increases in aggression over the following years. There was a preponderance of males in that subgroup (58.6\% of the group). The most common pattern (shown by $58 \%$ of the sample) was a display of aggression at moderate rates, with a less dramatic increase from 17 to 42 months. This 'modest aggression' group was divided equally between girls and boys. Thus more boys than girls were on the high-level trajectory, but some boys showed low levels and some girls showed high levels of aggression.

The trajectory analyses conducted by Tremblay and colleagues compared girls and boys at the same chronological ages; such comparisons do not necessarily take into account the maturational advantage held by girls. Thus, it is not clear whether the girls displaying the low-level pattern had previously shown higher levels of physical aggression but had desisted sooner than their male age-mates. Our own observations in a short-term longitudinal study of British toddlers suggested that desistance from aggression might occur later for boys (Hay et al. 2000). In the first of two home visits, a majority of 1- to 2-year-old boys deployed force against a familiar peer at least once; by contrast, most girls never used force against their peers. By the time of the second visit, 6 months later, most boys as well as most girls had desisted from physical aggression.
It is clear from the trajectory studies that any evidence for an overall pattern of earlier desistance by girls must be tempered by an appreciation of the striking individual differences in rates of aggression already evident by the second year of life. Individual differences in aggression emerge sooner for girls than for boys (Hay et al. 2000; Rubin et al. 2003). This implies that girls at risk for aggressive conduct problems may be detected quite early in development.

\section{Hypothesis 3: Boys play in more active ways that spill over into aggression}

It has long been observed that boys and girls prefer different types of play and different types of toys. To the extent that parents attribute different interests to girls and boys, and provide them with different play items (Rheingold \& Cook, 1975; Nash \& Krawczyk, 1994), girls' and boys' interests increasingly diverge, so that, by childhood's end, they can indeed be seen as inhabiting parallel social worlds (Maccoby, 1998). In gender-segregated peer groups, boys' preferences for stereotypically masculine toys and more active play might foster rougher behaviour, which promotes conflict. Higher rates of aggression in boys' interactions with other boys might be an epiphenomenon, emerging only because boys spend time with other boys, doing the sorts of things that lead to conflict. For example, preschool-aged boys are significantly more likely than girls to show rambunctious and provocative behaviour (Hay et al. unpublished observations).

Boys are certainly more likely than girls are to engage in rough-and-tumble play. Play fighting is seen in a variety of mammalian species, and has constructive social functions (Pellis et al. 2005). Do higher rates of rough-and-tumble play spill over into higher rates of aggression? Or can rough-and-tumble play be seen as a control mechanism, controlling and perhaps reducing male aggression? It has been argued that exposure to rough-and-tumble play is a socialization experience typically provided by fathers, which acts to control boys' levels of aggression; however, analyses designed to test this proposition provided no evidence for this hypothesis (Paquette et al. 2003). 
It seems likely that male peer groups develop social norms governing play and response to the provocations of others, which foster a moderate level of aggression (Dishion et al. 2002). To the extent that boys play mainly with other boys, the minority influence of highly aggressive boys will encourage physical aggression in boys' groups, even if most boys are simply defending their own possessions and position in the group. Such social psychological processes, building on biologically based activity levels and preferences, would contribute to a widening gap between boys and girls.

\section{Hypothesis 4: Girls' aggression becomes increasingly covert}

Meanwhile, girls' groups develop their own social norms. Do girls desist completely from aggression, or do they simply hide their aggressive acts from the scrutiny of adults? In common with other areas of psychology, the study of the development of aggression needs to make a distinction between competence and performance. Although both sexes possess the ability to be aggressive (an 'aggressive competence'), girls become increasingly less likely to perform aggressive acts. The growing gender gap may be partly due to effective socialization pressures that curb aggression in girls. If so, what happens to girls reflects one of the most successful intervention programmes ever attempted. But do girls really stop being aggressive?

It is certainly true that feminine aggression never disappears entirely. Aggression occurs when adults are not close by; an observational study using radio microphones confirmed that girls tended to be more physically aggressive on the far side of the playground than when they were in close proximity to teachers (Pepler \& Craig, 1991). This finding suggests that, for girls, aggression becomes a private, not a public, phenomenon. If so, reports from adult informants will underestimate girls' aggressive conduct problems (Cairns et al. 1989; Hay \& Pawlby, 2003). It is certainly clear that girls commonly engage in aggression in the privacy of their own homes, in disputes with their siblings (e.g. Martin \& Ross, 2005).

Pepler and Craig's observations also suggest that girls are generally more sensitive to the opinions of adults than boys are, and perhaps more amenable to socialization pressures to desist from aggression. By the age of 5, girls are significantly more likely than boys to show a 'socialized' response to an adult interviewer's questions about what they would do in conflict with peers, saying that they would 'ask nicely' and 'say please' (Hay et al. 1992). This more socialized approach to interpersonal conflict emerges at about the same time as the sex difference in aggression becomes evident. Twoyear-old girls are more likely than their male peers to use such socialized speech; they use manners and refer to possession rights and prosocial solutions to conflict while in disputes with familiar peers (Hay et al. unpublished observations).

Thus it becomes important to study the extent to which socialization pressures are applied to the early aggressive behaviour shown by girls as opposed to boys (Fagot \& Hagen, 1985). Are parents and other adults more likely to ignore or even admire boys' aggression? Are they more likely to encourage boys to defend themselves in conflict with siblings and peers? Observations of young children reveal that parents are more likely to tolerate aggression when it is shown by a boy (Martin \& Ross, 2005). Girls, as opposed to boys, are more likely to be required to relinquish their claims to an object in dispute (Ross et al. 1990). Perhaps because of such pressures, in conflicts with mothers, siblings and friends, girls are more likely to show submissive behaviour (Dunn \& Herrera, 1997). Thus, girls are under considerable pressure to desist from aggression. Such social pressure may force overt aggression underground.

\section{Hypothesis 5: Girls show qualitatively different kinds of aggression}

For decades, many investigators have argued that girls engage in aggression in qualitatively different ways, preferring to use 'verbal' (Muste \& Sharpe, 1947), 'indirect' (Vaillancourt, 2005), 'social' (Paquette \& Underwood, 1999) or 'relational aggression' (Crick, 1995; Crick et al. 1997). Taking into account some differences in nuance, and the fact that there is no consistent evidence for sex differences in the use of verbal invective, these investigators have all emphasized the fact that girls may be more prone than 
boys are to inflict hurt on others through words and manipulation of interpersonal relationships, rather than merely using their fists. Inattention to such phenomena leads to biased estimates of girls' conduct problems (Zoccolillo, 1993).

Preschool children already use indirect aggression (e.g. Ostrov \& Keating, 2004), but its study is not without methodological complexity. Females are not only more likely to engage in indirect aggression, they are also more likely to spot it when it occurs; male observers are significantly less likely to identify instances of relational aggression in preschool children (Ostrov et al. 2005). Different informants do not always agree (McEvoy et al. 2003). Perhaps because of such methodological problems, studies of preschool children do not provide consistent evidence for sex differences. In some cases, boys are more likely to use both forms of aggression (e.g. McEvoy et al. 2003).

It is possible that this hypothesis needs to be rephrased. Perhaps girls and women tend to deploy aggression, physical and verbal, direct and indirect, in the context of close personal relationships (Moffitt et al. 2001). Girls fight with their brothers and sisters, women smack their children, and women and men both engage in violent behaviour in romantic relationships (e.g. Krueger et al. 1998; Capaldi \& Owen, 2001). In the large Dunedin sample, women were more likely than men to report abusing their partners; in a clinical subsample of highly violent couples, women and men abused their partners at similar rates (Moffitt et al. 2001). A growing tendency to confine aggression to close relationships may be one of the reasons why girls' aggression disappears from public view (Pepler \& Craig, 1991).

\section{Hypothesis 6: The sex difference in aggression is due to boys' higher rates of developmental and psychological problems}

The sex difference in aggression may be produced primarily by a subgroup of boys with clinical disorders, who are disproportionately represented in the high, stable trajectory detected in longitudinal studies (Moffitt et al. 2001; Broidy et al. 2003; NICHD Early Child Care Research Network, 2004; Côté et al. 2006). Boys are generally more susceptible to the clinical disorders that present in early childhood (Rutter et al. 2003). Rates of neurodevelopmental difficulties and childhood disorder are higher in young males (Rutter et al. 2003; Raine et al. 2005; Messer et al. 2006). Conduct disorder is co-morbid with attention deficit hyperactivity disorder (ADHD) and emotional disorders (e.g. Thapar et al. 2001; Lahey et al. 2002). Links between ADHD and overt aggression are found for girls as well as boys (Abikoff et al. 2002), but the preponderance of boys with ADHD symptoms assuredly contributes to the overall sex difference in aggression.

Specific deficits in emotional and cognitive functioning, even at subclinical levels, contribute to elevated aggression in the population of young males. In the emotional realm these include problems with the regulation of emotion, including fearlessness in the face of novelty and challenge (Raine et al. 1998; van Goozen, 2005); problems in regulating negative emotionality in social situations (Eisenberg et al. 1995; Hughes et al. 2000); and deficits in the understanding of emotion, which predict boys' later aggression (Denham et al. 2002). Associations between emotional functioning and aggression are found across cultures (e.g. Eisenberg et al. 2000). This implies that aggression may be underpinned by problems in the brain systems that underlie the expression and understanding of emotion; there is considerable theoretical interest in the relationship between antisocial behaviour and responses to stress, in terms of autonomic functioning and the hypothalamic-pituitary-adrenal (HPA) axis (Raine, 2002; van Goozen, 2005).

Aggressive children also have problems in attention and cognition. Aggression is associated with low general IQ and symptoms of ADHD (e.g. Hay et al. 2003), executive function deficits (e.g. Hughes et al. 2000; Séguin \& Zelazo, $2005)$; problems in acquiring a theory of mind (Capage \& Watson, 2001; Hughes \& Ensor, 2006) and difficulties in social problem-solving (Schwartz et al. 1998). Aggression is linked to frontal deficits (Raine, 2002; Forbes et al. 2006). Thus, the early emergence of a high, stable aggressive trajectory (with its preponderance of boys) may result from boys' higher risk for deficits in emotion regulation and cognitive function (Raine et al. 2005). 


\section{Hypothesis 7: Boys are more likely to show aggression in response to situational triggers}

The social psychological study of aggression has always emphasized situational cues and social circumstances that trigger aggressive responses, including the presence of weapons (Berkowitz \& LePage, 1967), the experience of frustration (Dollard et al. 1939) and exposure to violent media (e.g. Bandura et al. 1963). Difficulties in regulating emotion and processing the details of social situations lower the threshold for an aggressive response to challenging situations. Aggressive reactions to situational triggers would thus contribute to the overall level of male aggression.

However, it is important to consider individual differences that might underlie the overall sex difference. Aggressive children run to opposite extremes. Some are highly emotionally expressive; others show little emotion. Some have social problem-solving deficits; others manipulate other people with Machiavellian precision. In other words, some children respond aggressively to challenging situations, while others deliberately command situations to inflict harm on others.

For some children, aggression occurs as part of an emotional reaction to challenging situations. For example, 2-year-old boys whose aggression was characterized as emotionally dysregulated were especially likely to have clinically significant externalizing problems 3 years later (Cummings et al. 1989). Children who show such reactive, emotional aggression may have problems in processing what is going on in social situations (Dodge \& Coie, 1987) and may be hyper-responsive to stress (Gunnar et al. 1997).

By contrast, some highly violent individuals show a very different pattern, being relatively unemotional, proactive and strategic in the use of aggression. Such 'callous-unemotional' aggression is often accompanied by fearlessness (Raine et al. 1998), a failure to recognize sad and fearful emotions in others (Stevens et al. 2001) and hypo-responsivity to stress (McBurnett et al. 2000). Rather than showing deficits in social problem-solving, these children may evince considerable skill in understanding and manipulating other people (Sutton et al. 1999).
Although differential rates of proactive and reactive aggression might contribute to the overall sex difference in rates of aggression, it is not clear whether boys are disproportionately represented in one or both subtypes of aggressive youngsters. Some studies only tested boys (Dodge \& Coie, 1987; Vitaro et al. 2002), and the others do not show a consistent pattern of difference between the sexes (Vitaro \& Brendgan, 2005). Perhaps some boys run to each extreme, which would exaggerate the overall sex difference in total aggression.

\section{Hypothesis 8: Boys are more strongly affected by adverse rearing environments}

Many well-known environmental risk factors are associated with aggression and related conduct problems, including prenatal insults, social disadvantage, parental antisocial behaviour, parental psychopathology, disrupted relationships with parents, maltreatment, family discord and divorce (Loeber \& Hay, 1997). Are boys especially affected by these environmental insults? In comparison to girls, young boys show more aggression and other conduct problems in response to insecure attachment relationships (e.g. Turner, 1991), harsh discipline from fathers (Chang et al. 2003) and parental psychopathology (Hay et al. 1992; Shaw et al. 1994; Hipwell et al. 2005; but see Hay et al. 2003). In the Dunedin sample, family adversity during childhood and adolescence had a greater effect on males than females, although the effect sizes were not large (Moffitt et al. 2001). A recent study of disruptive behaviour disorders in a national sample of 5- to 11-year-olds found no evidence for boys' and girls' differential sensitivity to social risk (Messer et al. 2006); however, it is possible that differential sensitivity during early development, including the prenatal months, contributes to the high-risk trajectory followed by some boys.

Several plausible mechanisms might underlie male sensitivity to the rearing environment. Adversity might increase young boys' exposure to violence, which promotes aggression (Schwartz \& Proctor, 2000); alternatively, early adversity may disrupt normally occurring selfregulatory processes (Gunnar \& Donzella, 2002), and the general maturational lag in males may exacerbate such effects. Thus, the deficits in 
regulation of emotion and cognition that are associated with violence may be partly derived from adversity in the antenatal or early postnatal environment.

Nevertheless, it is impossible to evaluate this hypothesis without attention to genetic influence; environmental adversity operates in the context of genetic predispositions to influence the development of antisocial behaviour (Moffitt, 2005). For example, a twin study of aggressive behaviour in the toddler years documented genetic influence as well as influence of the shared environment impinging on both members of a twin pair, whether or not they are identical (Dionne et al. 2003). However, in that sample, no evidence for sex differences in aggression was obtained. Complex interactions between genes and adverse environments may eventually help to explain why boys are more likely than girls to follow trajectories to serious violence. However, the genetic evidence currently available does not yet explain the rising trajectory of aggressive behaviour in young boys. Indeed, a meta-analysis of genetically informative studies of antisocial behaviour showed that the estimates of genetic influence are similar for the two sexes (Rhee \& Waldman, 2002).

\section{CONCLUSIONS}

The evidence suggests that, when aggression first emerges in the human repertoire, sex differences are not readily apparent. Over the course of the first 4 years of life, girls and boys become increasingly differentiated in both the extent and nature of their aggressive behaviour. No single hypothesis provided a complete explanation of the developmental trends that have been identified. Rather, the increasing gender gap in aggression can best be understood in reference to three general principles:

(1) Girls mature sooner than boys do; their precocity appears to protect them against aggression, although, during puberty, it may place them more at risk for the emotional disorders of adolescence and associated conduct problems. In early childhood, female precocity means that the average 2 -year-old girl is biologically prepared for socialization. In other words, girls are biologically more susceptible than boys are to the social pressures that promote desistance from aggression.

(2) Gender differences derive from individual differences, and are strongly influenced by a subgroup of vulnerable males. Children with emotional and cognitive problems are more aggressive and, in infancy and early childhood, boys are at elevated risk for emotional and cognitive problems. Thus, the general trend for boys to be more aggressive than girls is largely accounted for by a minority of troubled boys who engage in aggression at high rates.

(3) Sex is a salient social category for young children, who retreat into gendered social worlds in early childhood and begin to hold extreme views about differences between the sexes (Gelman et al. 2004). In the privacy of those gender-segregated peer groups, boys play in ways that may promote aggression. The minority of highly aggressive boys raise the overall level of aggression in their male peer groups. Less aggressive boys may need to fight back against their highly aggressive peers, and adults often encourage them to do so. Meanwhile, girls develop distinct ways of manipulating the social world, which often include verbal taunts and indirect aggression. Girls confine their most violent actions to close, personal relationships (Moffitt et al. 2001).

By the time children enter formal education, a small minority of girls and rather more boys still deploy force at high rates. They are at risk for a broad range of emotional and behavioural problems in later childhood and adolescence. By contrast, moderate and declining levels of aggression in the toddler years, shown by equal numbers of girls and boys (Tremblay et al. 2004), do not necessarily lead to poor outcomes for either sex (Campbell et al. 2006).

It is important to recognize that girls and boys start out with similar levels of aggression. Unqualified acceptance of the common wisdom that aggression is a normative part of boyhood impedes detection of those highly aggressive girls and boys whose problems persist into later life. 


\section{DECLARATION OF INTEREST}

None.

\section{REFERENCES}

Abikoff, H. B., Jensen, P. S., Arnold, L. L. E., Hoza, B., Hechtman, L., Pollack, S., Martin, D., Alvir, J., March, J. S., Hinshaw, S., Vitiello, B., Newcorn, J., Greiner, A., Conners, C. K., Elliot, G., Greenhill, L., Kraemer, H., Pelham, W. E., Severe, J. B., Swanson, J. M., Wells, K. \& Wigal, T. (2002). Observed classroom behavior of children with ADHD: relationship to gender and comorbidity. Journal of Abnormal Child Psychology 30, 349-359.

Alink, L. R. A., Mesman, J., van Zeijl, J., Stolk, M. N., Juffer, F., Koot, H. M., Bakermans-Kranenburg, M. J. \& van Ijzendoorn, M. H. (2006). The early childhood aggression curve: development of physical aggression in 10- to 50-month-old children. Child Development 77, 954-966.

Archer, J. \& Côté, S. (2005). Sex differences in aggressive behavior : a developmental and evolutionary perspective. In Developmental Origins of Aggression (ed. R. Tremblay, W. W. Hartup and J. Archer), pp. 425-443. Guilford: New York.

Bakeman, R. \& Brownlee, J. R. (1982). Social rules governing object conflicts in toddlers and preschoolers. In Peer Relations and Social Skills in Childhood (ed. K. H. Rubin and H. S. Ross), pp. 99-110. Springer-Verlag: New York.

Bandura, A., Ross, D. \& Ross, S. A. (1963). Imitation of filmmediated aggressive models. Journal of Abnormal and Social Psychology 66, 3-11.

Berkowitz, L. \& LePage, A. (1967). Weapons as aggression-eliciting stimuli. Journal of Personality and Social Psychology 7, 202-207.

Broidy, L., Nagin, D. S., Tremblay, R. E., Bates, J., Brame, B., Dodge, K. A., Fergusson, D., Horwood, J. L., Loeber, R., Laird, R., Lynam, D. R., Moffitt, T. E. \& Pettit, G. S. (2003). Developmental trajectories of childhood disruptive behaviors and adolescent delinquency: a six-site, cross-national study. Developmental Psycho$\log y$ 39, 222-245.

Brooks-Gunn, J. \& Lewis, M. (1979). The effects of age and sex on infants' playroom behavior. Journal of Genetic Psychology 134, 99-105.

Cairns, R. B., Cairns, B. D., Neckerman, H. J., Ferguson, L. I. \& Gariépy, J.-L. (1989). Growth and aggression: childhood to early adolescence. Developmental Psychology 25, 320-330.

Cairns, R. B. \& Kroll, A. (1994). Developmental perspective on gender differences and similarities. In Development through Life: A Handbook for Clinicians (ed. M. Rutter and D. F. Hay), pp. 350-372. Blackwell Scientific: Oxford.

Campbell, S. B., Spieker, S., Burchinal, M. \& Poe, M. D. (2006). Trajectories of aggression from toddlerhood to age 9 predict academic and social functioning through age 12. Journal of Child Psychology and Psychiatry 47, 791-800.

Capage, L. \& Watson, A. C. (2001). Individual differences in theory of mind, aggressive behavior, and social skills in young children. Early Education and Development 12, 613-628.

Capaldi, D. M. \& Owen, L. D. (2001). Physical aggression in a community sample of at-risk young couples: gender comparisons for high frequency, injury, and fear. Journal of Family Psychology 15, 425-440.

Caplan, M., Vespo, J. E., Pedersen, J. \& Hay, D. F. (1991). Conflict and its resolution in small groups of one- and two-year-olds. Child Development 62, 1513-1524.

Chang, L., Schwartz, D., Dodge, K. A. \& McBridge-Change, C. (2003). Harsh parenting in relation to child emotion regulation and aggression. Journal of Family Psychology 17, 598-606.

Côté, S., Vaillancourt, T., LeBlanc, J. C., Nagin, D. S. \& Tremblay, R. E. (2006). The development of physical aggression from toddlerhood to pre-adolescence: a nation wide longitudinal study of Canadian children. Journal of Abnormal Child Psychology 34, 71-85.
Crick, N. R. (1995). Relational aggression: the role of intent attributions, feelings of distress and provocation type. Development and Psychopathology 7, 313-322.

Crick, N. R., Casas, J. F. \& Mosher, M. (1997). Relational and overt aggression in preschool. Child Development 33, 579-588.

Cummings, E. M., Iannotti, R. J. \& Zahn-Waxler, C. (1989). Aggression between peers in early childhood: individual continuity and change. Child Development 60, 887-895.

Denham, S. A., Caverly, S., Schmidt, M., Blair, K., DeMulder, E., Casi, S., Hamada, H. \& Mason, T. (2002). Preschool understanding of emotions: contributions to classroom anger and aggression. Journal of Child Psychology and Psychiatry 43, 901-916.

Dionne, G., Tremblay, R. E., Boivin, M., Laplante, D. \& Pérusse, D. (2003). Physical aggression and expressive vocabulary in 19 month-old twins. Developmental Psychology 39, 261-273.

Dishion, T. J., Bullock, B. M. \& Granic, I. (2002). Pragmatism in modeling peer influence: dynamics, outcomes, and change processes. Development and Psychopathology 14, 969-981.

Dodge, K. A. \& Coie, J. D. (1987). Social information processing factors in reactive and proactive aggression in children's peer groups. Journal of Personality and Social Psychology 53, 1146 1158 .

Dollard, J., Doob, L., Miller, N. E., Mowrer, O. H. \& Sears, R. R. (1939). Frustration and Aggression. Yale University Press: New Haven.

Dunn, J. \& Herrera, C. (1997). Conflict resolution with friends, siblings, and mothers: a developmental perspective. Aggressive Behavior 23, 343-357.

Eckerman, C. O., Whatley, J. \& Kutz, S. L. (1975). Growth of social play with peers during the second year of life. Developmental Psychology 11, 42-49.

Egger, H. L. \& Angold, A. (2006). Common emotional and behavioral disorders in preschool children: presentation, nosology, and epidemiology. Journal of Child Psychology 47, 313-337.

Eisenberg, N., Fabes, R. A., Murphy, B., Maszk, P., Smith, M. \& Karbon, M. (1995). The role of emotionality and regulation in children's social functioning: a longitudinal study. Child Development 66, 1360-1384.

Eisenberg, N., Pidada, S. \& Liew, J. (2000). The relations of regulation and negative emotionality to Indonesian children's social functioning. Child Development 72, 1747-1763.

Fagot, B. I. \& Hagan, R. (1985). Aggression in toddlers: responses to the assertive acts of boys and girls. Sex Roles 12, 341-351.

Forbes, E. E., Shaw, D. S., Fox, N. A., Cohn, J. F., Silk, J. S. \& Kovacs, M. (2006). Maternal depression, child frontal asymmetry, and child affective behavior as factors in child behavior problems. Journal of Child Psychology and Psychiatry 47, 79-87.

Gelman, S. A., Taylor, M. G. \& Nguyen, S. P. (2004). Mother-child conversations about gender. Monographs of the Society for Research in Child Development 69, Issue 1, vii-145.

Gunnar, M. R. \& Donzella, B. (2002). Social regulation of the cortisol levels in early human development. Psychoneuroendocrinology 27, 199-220.

Gunnar, M. R., Tout, K., de Haan, M., Pierce, S. \& Stansbury, K. (1997). Temperament, social competence, and adrenocortical activity in preschoolers. Developmental Psychobiology 31, 65-85.

Hay, D. F. (2005). The beginnings of aggression in infancy. In Developmental Origins of Aggression (ed. R. Tremblay, W. W. Hartup and J. Archer), pp. 107-132. Guilford: New York.

Hay, D. F. (2006). 'Yours and mine': toddlers' talk about possession with familiar peers. British Journal of Developmental Psychology 24, 39-52.

Hay, D. F., Castle, J. \& Davies, L. (2000). Toddlers' use of force against familiar peers: a precursor of serious aggression? Child Development 71, 457-467.

Hay, D. F. \& Pawlby, S. (2003). Prosocial development in relation to children's and mother's psychological problems. Child Development 74, 1314-1327.

Hay, D. F., Pawlby, S., Angold, A., Harold, G. T. \& Sharp, D. (2003). Pathways to violence in the children of mothers who were depressed postpartum. Developmental Psychology 39, 1083-1094. 
Hay, D. F. \& Ross, H. S. (1982). The social nature of early conflict. Child Development 53, 105-113.

Hay, D. F., Zahn-Waxler, C., Cummings, E. M. \& Iannotti, R. (1992). Young children's views about conflict with peers: a comparison of the daughters and sons of depressed and well women. Journal of Child Psychology and Psychiatry 33, 669-683.

Hipwell, A., Murray, L., Ducournau, P. \& Stein, A. (2005). The effects of maternal depression and parental conflict on children's peer play. Child Care, Health and Development 31, 11-23.

Hollenberg, E. \& Sperry, M. (1951). Some antecedents of aggression and effects of frustration in doll play. Journal of Personality $\mathbf{1}$, $32-43$.

Holmberg, M. C. (1980). The development of social interchange patterns from 12 to 42 months. Child Development 51, 448-456.

Hughes, C. \& Ensor, R. (2006). Behavioural problems in 2-year-olds: links with individual differences in theory of mind, executive function and harsh parenting. Journal of Child Psychology and Psychiatry 47, 488-497.

Hughes, C., White, A., Sharpen, J. \& Dunn, J. (2000). Antisocial, angry and unsympathetic: 'hard-to-manage' preschoolers' peer problems and possible cognitive influences. Journal of Child Psychology and Psychiatry 41, 169-179.

Keenan, K. \& Shaw, D. (1997). Developmental and social influences on young girls' early problem behavior. Psychological Bulletin 121, $95-113$

Kim-Cohen, J., Arseneault, L., Caspi, A., Tomas, M. P., Taylor, A. \& Moffitt, T. E. (2005). Validity of DSM-IV conduct disorder in $4 \frac{1}{2}-$ to 5-year-old children. American Journal of Psychiatry 162, 1108 1117.

Koops, W. (2001). Aggressive Developmental Psychology. Inaugural lecture. University Press: Utrecht.

Krueger, R. F., Moffitt, T. E., Bieske, A. \& Silva, P. A. (1998) Assortative mating for antisocial behavior: developmental and methodological implications. Behavior Genetics 28, 173-186.

Lahey, B. B., Loeber, R., Burke, J., Rathouz, P. J. \& McBurnett, K. (2002). Waxing and waning in concert: dynamic comorbidity of conduct disorder with other disruptive and emotional problems over 7 years among clinic-referred boys. Journal of Abnormal Psychology 111, 556-567.

Loeber, R. \& Hay, D. F. (1997). Key issues in the development of aggression and violence from childhood to early adulthood. Annual Review of Psychology 48, 371-410.

Maccoby, E. E. (1998). The Two Sexes: Growing Up Apart, Coming Together. Harvard University Press: Cambridge, MA.

Maccoby, E. E. \& Jacklin, C. (1974). The Psychology of Sex Differences. Stanford University Press: Stanford, CA.

Martin, J. L. \& Ross, H. S. (2005). Sibling aggression: sex differences and parents' reactions. International Journal of Behavioral Development 29, 129-138.

McBurnett, K., Lahey, B. B., Rathouz, P. J. \& Loeber, R. (2000). Low salivary cortisol and persistent aggression in boys referred for disruptive behavior. Archives of General Psychiatry 57, $38-43$.

McEvoy, M. A., Estrem, T. A., Rodriguez, M. C. \& Olson, M. L. (2003). Assessing relational and physical aggression among preschool children: intermethod agreement. Topics in Early Childhood Special Education 23, 53-63.

Messer, J., Goodman, R., Rowe, R., Meltzer, H. \& Maughan, B. (2006). Preadolescent conduct problems in girls and boys. Journal of the American Academy of Child and Adolescent Psychiatry 45, 184-191.

Moffitt, T. E. (2005). The new look of behavioral genetics in developmental psychopathology: gene-environment interplay in antisocial behaviors. Psychological Bulletin 131, 533-554.

Moffitt, T. E., Caspi, A., Rutter, M. \& Silva, P. A. (2001). Sex Differences in Antisocial Behaviour. Conduct Disorder, Delinquency and Violence in the Dunedin Longitudinal Study. Cambridge University Press: Cambridge, UK.

Muste, M. J. \& Sharpe, D. I. (1947). Some influential factors on the determination of aggressive behavior in preschool children. Child Development 51, 823-829.
Nash, A. \& Krawczyk, R. (1994). Children's rooms in the 90s. Presentation to the Conference on Human Development. Pittsburgh, PA, USA, April 1994.

NICHD Early Child Care Research Network (2004). Trajectories of physical aggression from toddlerhood to middle childhood. Monographs of the Society for Research in Child Development 69 , Issue 4, vii-146.

Ostrov, J. M. \& Keating, C. F. (2004). Gender differences in preschool aggression during free play and structured interactions: an observational study. Social Development 13, 255-277.

Ostrov, J., Crick, N. R. \& Keating, C. F. (2005). Gender-biased perceptions of preschoolers' behavior: how much is aggression and prosocial behavior in the eye of the beholder? Sex Roles 52, 393-398.

Paquette, D., Carbonneau, R., Dubeau, D., Bigras, M. \& Tremblay, R. E. (2003). Prevalence of father-child rough-and-tumble play and physical aggression in preschool children. European Journal of the Psychology of Education 18, 171-189.

Paquette, J. A. \& Underwood, M. K. (1999). Gender differences in young adolescents' experiences of peer victimization: social and physical aggression. Merrill-Palmer Quarterly 45, 242-266.

Pellis, S. M., Pellis, V. C. \& Foroud, A. (2005). Play fighting: aggression, affiliation and the development of nuanced social skills. In Developmental Origins of Aggression (ed. R. Tremblay, W. W. Hartup and J. Archer), pp. 47-62. Guilford: New York.

Pepler, D. J. \& Craig, W. (1991). A peek behind the fence: naturalistic observations of aggressive children with remote audiovisual recording. Developmental Psychology 31, 548-553.

Raine, A. (2002). Annotation: the role of prefrontal deficits, low autonomic arousal, and early health factors in the development of antisocial and aggressive behavior in children. Journal of Child Psychology and Psychiatry 43, 417-434.

Raine, A., Moffitt, T. E., Caspi, A., Loeber, R., Stouhamer-Loeber, M. \& Lynam, D. (2005). Neurocognitive impairments in boys on the life-course persistent antisocial path. Journal of Abnormal Psychology 114, 38-49.

Raine, A., Reynolds, C., Venables, P., Mednick, S. \& Farrington, D. P. (1998). Fearlessness, stimulation-seeking, and large body size at age 3 years as early predispositions to childhood aggression at age 11 years. Archives of General Psychiatry 55, 745-751.

Rheingold, H. L. \& Cook, K. V. (1975). The contents of boys' and girls' rooms as an index of parents' behaviour. Child Development 46, 459-463.

Rhee, S. H. \& Waldman, I. D. (2002). Genetic and environmental influences on antisocial behavior: a meta-analysis of twin and adoption studies. Psychological Bulletin 128, 490-529.

Ross, H., Tesla, C., Kenyon, B. \& Lollis, S. (1990). Maternal intervention in toddler peer conflict: the socialization of principles of justice. Developmental Psychology 26, 994-1003.

Rubin, K. H., Burgess, K. B., Dwyer, K. M. \& Hastings, P. D. (2003). Predicting preschoolers' externalizing behaviors from toddler temperament, conflict, and maternal negativity. Developmental Psychology 39, 164-176.

Rubin, K. H., Hastings, P., Stewart, S. \& McNichol, K. (1998), Intrapersonal and maternal correlates of aggression, conflict, and externalising problems in toddlers. Child Development 69, 1614 1629.

Rutter, M., Caspi, A. \& Moffitt, T. E. (2003). Using sex differences in psychopathology to study causal mechanisms: unifying lessons. Journal of Child Psychology and Psychiatry 44, 1092-1115.

Schwartz, D., Dodge, K. A., Coie, J. D., Hubbard, J. A., Cillessen, A. H., Lemerise, E. A. \& Bateman, H. (1998). Socialcognitive and behavioral correlates of aggression and victimization in boys' play groups. Journal of Abnormal Child Psychology 26, 431-440.

Schwartz, D. \& Proctor, L. J. (2000). Community violence exposure and children's social adjustment in the school peer group: the mediating roles of emotion regulation and social cognition. Journal of Consulting and Clinical Psychology 68, 670-683.

Séguin, J. R. \& Zelazo, P. D. (2005). Executive function in early physical aggression. In Developmental Origins of Aggression 
(ed. R. Tremblay, W. W. Hartup and J. Archer), pp. 307-329. Guilford: New York.

Shaw, D. S., Vondra, J. I., Hommerding, K. D., Keenan, K. \& Dunn, M. (1994). Chronic family adversity and early child behavior problems: a longitudinal study of low income families. Journal of Child Psychology and Psychiatry 35, 1109-1122.

Stevens, D., Charman, T. \& Blair, R. J. R. (2001). Recognition of emotion in facial expressions and vocal tones in children with psychopathic tendencies. Journal of Genetic Psychology 162, 201-211.

Sutton, J., Smith, P. K. \& Swettenham, J. (1999). Bullying and 'theory of mind': a critique of the 'social skills deficit' view of antisocial behaviour. Social Development 8, 117-127.

Thapar, A., Harrington, R. \& McGuffin, P. (2001). Examining the comorbidity of ADHD-related behaviours and conduct problems using a twin study design. British Journal of Psychiatry 179, 224-229.

Tremblay, R. E. (2000). The development of aggressive behaviour during childhood: what have we learned in the past century? International Journal of Behavioural Development 24, 129-141.

Tremblay, R. E. \& Nagin, D. S. (2005). The developmental origins of physical aggression in humans. In Developmental Origins of Aggression (ed. R. E. Tremblay, W. W. Hartup and J. Archer), pp. 83-106. Guilford: New York.

Tremblay, R., Nagin, D. S., Séguin, J. R., Zoccolillo, M., Zelazo, P. D., Boivin, M., Pérusse, D. \& Japel, C. (2004). Physical aggression during early childhood: trajectories and predictors. Pediatrics 114, e43-e50.
Turner, P. J. (1991). Relations between attachment, gender, and behavior with peers in preschool. Child Development 62, 14751488.

Vaillancourt, T. (2005). Indirect aggression among humans: social construct or evolutionary adaptation? In Developmental Origins of Aggression (ed. R. Tremblay, W. W. Hartup and J. Archer), pp. 158-177. Guilford: New York.

van Goozen, S. H. M. (2005). Hormones and the developmental origins of aggression. In Developmental Origins of Aggression (ed. R. Tremblay, W. W. Hartup and J. Archer), pp. 281-306. Guilford: New York

van Zeijl, J., Mesman, J., Stolk, M. N., Alink, L. R. A., van Ijzendoorn, M. H., Bakermans-Kranenburg, M. J., Juffer, F. \& Koot, H. M. (2006). Terrible ones? Assessment of externalizing behaviors in infancy with the Child Behavior Checklist. Journal of Child Psychology and Psychiatry 47, 801810.

Vitaro, F. \& Brendgen, M. (2005). Proactive and reactive aggression: a developmental perspective. In Developmental Origins of Aggression (ed. R. Tremblay, W. W. Hartup and J. Archer), pp. 281-306. Guilford: New York.

Vitaro, F., Brendgen, M. \& Tremblay, R. (2002). Reactively and proactively aggressive children: antecedent and subsequent characteristics. Journal of Child Psychology and Psychiatry 43 , 495-505.

Zoccolillo, M. (1993). Gender issues in conduct disorder. Development and Psychopathology 5, 65-78. 